\title{
10
}

\section{Domestic market integration and inter-regional growth spillovers}

\author{
Jane Golley and Nicolaas Groenewold
}

While China's integration into the global economy during the past three decades has been extremely impressive, the integration among regions within China has been much less so. Domestic market integration has a critical role to play in binding together a country that has suffered from disintegrative tendencies throughout its history. As such, the importance of integration cannot be overstated, particularly in light of recent research that seems 'to confirm the pertinence of alarming forecasts concerning the danger of China's move towards internal disintegration' (Poncet 2003:17). Numerous other researchers have reached similar-if not quite as dramatic — conclusions in their analyses of China throughout the Communist era (Donnithorne 1967; Lyons 1987; Young 2000; World Bank 2005).

This chapter contributes to a growing literature that addresses the extent of domestic market integration in the Chinese economy. The next section defines integration and discusses the costs and benefits associated with it. This alone reveals that answering two of the most relevant questions-how integrated are China's provinces and how integrated should they be-is far from straightforward. A brief discussion of the numerous methodologies available for assessing the degree of integration further demonstrates this point and implies that our own method of empirical analysis-measuring inter-regional output spillovers-is only one part of a highly complicated picture.

The next section reviews the changing nature of Chinese domestic market integration during the Communist era. Regardless of the methodology employed, a salient feature of the discussion is the almost universal recognition 
that China's regions are less integrated than might be expected of regions in a unified nation-state. Our empirical results lend further support to this claim. A vector autoregressive (VAR) framework is introduced to assess the extent of output spillovers between six regions in China during the period from 1953 to 2003. The results suggest that while China's better-developed regions are relatively well interconnected with each other, spillovers between these regions are neither pervasive nor strong. Meanwhile, the least-developed regions-that is, those most in need of positive growth spillovers from elsewhere-are connected only weakly, if at all, with the rest of the country. Policy implications and recommendations are offered in the concluding section.

\section{Regional integration: theory and measurement}

Integration can be defined broadly as the increasing interdependence of regions, either within or across countries, as reflected in the flow of goods, services and/or factors of production. The process of integration requires the gradual elimination of economic frontiers and trade-restricting instruments between regions so that the mobility of goods, services and factors is not constrained. This process of 'integration from below' can be reinforced by 'integration from above', which entails the active promotion of economic cooperation between territories through appropriate policies or institutions (Tinbergen 1965).

The expansion of trade that arises due to falling trade barriers underpins one of the major benefits of integration. According to the standard neoclassical analysis, a reduction in trade barriers leads to welfare gains through the exploitation of comparative advantage and the consequent increase in productivity. Higher gross domestic product (GDP) growth rates occur during the transitional period-or the short term—in which resources are reallocated and capital accumulation takes place, as the economy approaches its new steady-state levels of capital and output per worker. Theories relating the gains from trade to long-term growth are based typically on models of endogenous technological change. ${ }^{1}$

Trade can increase the rate of technological progress-and hence productivity growth-either through an expansion of output markets enabling domestic producers to exploit economies of scale, or through an expansion of input markets resulting in lower production costs (for example, by giving domestic producers access to a wider variety of capital goods, effectively enlarging the base of productive knowledge, as described by Romer 1990). The gains from trade can be dynamic rather than static if specialisation stimulates productivity growth through learning by doing, as in Lucas (1988). On the flip side of these benefits, while trade can act as a conduit for technology transfer, 
theories of technological diffusion stress the importance of the host country (or region) having a sufficiently high level of 'social capability' in order to be able to successfully implement technologies developed in more advanced economies, while regions below a threshold level of development could be unable to make effective use of technology spillovers (see, for example, Abramovitz 1986 and Howitt 2000). That is, it is not guaranteed that all regions will be able to benefit equally from the trade that takes place between them, while some regions could miss out altogether. ${ }^{2}$

Beyond the trade-related benefits, integration should also improve the inter-regional transmission of growth from faster growing regions to lagging ones, through a variety of connections that are presumably stronger between highly integrated regions. These include the increase in imports from and investments in lagging regions, the diffusion of innovations originating in more rapidly growing regions and the ability of a more rapidly growing region to absorb some of the unemployed or underemployed labour from elsewhere. These effects all contribute to the equalisation of regional incomes, which is beneficial in itself from political and socioeconomic perspectives. With the hope that faster growing regions will exert a beneficial influence on other regions, however, comes the likelihood that more highly integrated markets will cause each other to suffer more when economic growth falters in any one region. Marshall (1920:241) describes how 'integration, that is, the growing intimacy and firmness of connections between separate parts of the industrial organism' enables each part of that organism 'to be less and less self-sufficient, to depend for its wellbeing more and more on other parts, so that any disorder in any part...will affect other parts also'. Moreover, while trickle-down effects are likely to be stronger across highly integrated regional markets, so too are their counterparts: 'polarisation' effects, which describe the adverse effects that rapid growth in better-developed regions can have on economic progress elsewhere (Hirschman 1958). These effects include the inability of comparatively inefficient, yet income-creating, industries in lagging regions to compete, 'brain drain' and capital depletion as savings are redirected towards more profitable investments in the rapidly growing regions.

While most arguments point to the long-term benefits of integration outweighing the costs, the same cannot necessarily be said of the short term. For example, in a developing economy, the freeing of restrictions on labour movements is likely to result in migrants moving to wealthier regions in search of higher wages. Meanwhile, the spread of innovation could remain tardy because of poor communication and transport links between the integrating regions. This combination would benefit the more rapidly growing regions to 
the detriment of poorer ones-an issue that resonates with the current Chinese situation. Thus, while integration is regarded generally as desirable, unless it proceeds far enough and in the right ways, a negative consequence of improved integration could be the worsening of regional disparities, in turn threatening the social stability and national unity that policymakers are trying to achieve.

Measuring the extent of integration in its various guises, let alone its costs and benefits, is fraught with difficulties. If the definition of regional integration was simplified to the removal of inter-regional trade barriers, the most direct way to measure the extent of integration would be to examine the prevalence of these barriers. The lack of tariffs, however, and other well-defined barriers to trade within a single nation make this simple approach inappropriate for our analysis here. Another direct approach examines inter-regional trade flows, based on the assumption that integration will result in rising trade flows. This method is problematic in China, given the paucity of inter-provincial trade data, although some attempts have been made (Naughton 2003; Poncet 2003, 2005). It is also problematic to distinguish the impact of integration from other factors influencing inter-regional trade, including transport costs and regional endowments.

The production approach assumes that the more integrated the regions, the more specialised the industry at the regional level, with changes in specialisation taken as evidence of changes in integration over time (Young 2000; Bai et al. 2004). One obvious shortcoming here is that much trade between regions can be intra-industry trade, which is consistent with similar industrial structures, not different ones. Alternatively, the marginal returns approach assesses factor returns in different regions, based on the assumption that these should converge in an integrated market (Tan and Zhang 2005), while similar methodologies can be used to assess price equality across regions, based on the law of one price (Parsley and Wei 1996; Fan and Wei 2003). The business cycle approach assumes that more closely integrated economies will exhibit strongly correlated business cycles (Xu 2002; Xu and Voon 2003; Tang 1998), and therefore focuses on the similarity of shocks across regions.

Of greater interest here, however, is the way in which shocks in one region are transmitted to others, based on the idea that more integrated regions will show stronger transmission of shocks. This brings us to the inter-regional growth spillover approach, which is described and adopted below, and which, simply speaking, seeks to identify how shocks to GDP in one region impact on GDP in that region and on GDP elsewhere, and how those impacts are transmitted over time. While this approach does not make it possible to draw strong conclusions regarding the precise transmission mechanisms between 
regions - that is, which trickle-down or polarisation effects are dominant-it does provide a useful starting point for further investigation into the issue. Before attempting this, however, the next section reviews the literature on regional integration in China during the Communist period.

\section{Regional integration in Communist $\mathrm{China}^{3}$}

Integration has been a central theme in explanations of economic development in the United States and other countries. In each case, the relationship between integration and development is complex and circular. Indeed, 'integration is perhaps best viewed not as a cause or result of development, but simply as an aspect of development itself' (Lyons 1987:14). This is the starting observation made by Lyons - in his seminal work on China's domestic market integration-who describes how the particular nature of China's planning system during the command era (1953-78) caused 'economic fragmentation' (or disintegration) along regional lines. Unlike the standard Soviet plan, China's plan was formulated and implemented primarily along provincial, rather than sectoral lines. The relative importance of regional units in the planning process meant that if inter-regional coordination was deficient-which it was-the disintegrative tendencies associated with compartmentalised planning would be felt largely along regional lines.

Various policies pursued by central and local governments reinforced the disintegrative nature of China's provincially focused planning mechanism. Donnithorne (1967) described how Mao Zedong's principle of self-reliance within administrative units created the incentive for self-sufficiency within those units. This strengthened the tendency towards a 'cellular economy' in which independent, comprehensive and relatively autarkic sub-systems at each and every geographic and sectoral unit were designed to operate independently. One negative consequence of this was increasing regional inequality, since '[i]n an administrative unit where economic drive and entrepreneurship is [sic] plentiful, the policy of self-reliance and self-sufficiency may give added encouragement to local initiative. Where these qualities are scarce, the likelihood of repairing this lack from elsewhere will be diminished' (Donnithorne 1972:612). The cellular economic structure and fragmentation that emerged during the period of command planning left a strong and lasting mark on inter-provincial relations. During the reform period, while the sources (and the wording) of the problem have changed, 'provincialism', local protectionism and the consequent lack of domestic market integration remain key policy issues.

The World Bank (1994) conducted the first major study of China's internal market developments during the reform period. Evidence of significant regional 
price differentials across a broad range of producer and consumer goods, combined with declining inter-provincial trade and investment flows, limited inter-provincial labour and capital mobility and bottlenecks in transport, led the bank to conclude that China was far from realising the benefits of its potentially large internal market. It called for the harmonisation of fees and fines levied on inter-provincial trade, the prohibition of inter-provincial trade barriers, changes in regulations affecting factor mobility and the removal of residual price controls.

While some of these issues have since been resolved, the essence of the problem remains, according to the World Bank's (2005) extensive report on the degree of integration in China's product and factor markets. In product markets, converging prices and increasing specialisation indicate increased integration, but new forms of protectionism-in local government procurement practices, for example-combined with the slow pace of institutional and transport infrastructure development, continue to impede the spread of growth across regions. Labour markets, while improving in recent years, still show significant fragmentation across regions and sectors. The bank's analysis of capital markets shows not only large misallocations across regions and sectors, it indicates that the degree of fragmentation has deteriorated over time. Key problems that remain include underdeveloped capital markets and large differences in the regulations and institutional and infrastructure environments that affect the relative attractiveness of different localities.

Young (2000) blames the lack of internal integration on the incompleteness of China's economic reforms. He begins with a story of the 'silkworm cocoon war' of the late 1980s, during which Zhejiang Province began to restrict the sale of silk cocoons to other parts of China, and silk factories in neighbouring Shanghai found it necessary to import raw silk from abroad. He then describes more generally how incremental economic reforms that devolved power to local governments resulted in competitive local industrial policies and the imposition of a variety of barriers to inter-provincial trade. Evidence of converging provincial industrial structures combined with fluctuating periods of converging and diverging provincial prices leads Young to conclude that 'the reform process led to the fragmentation of the domestic market and the distortion of regional production patterns away from comparative advantage' (2000:1,091). Replace 'reform' with 'planning' and the phrase could just as well be in Lyons' (1987) seminal work on fragmentation during the planning period.

Naughton (2003) presents the most optimistic analysis to date, disputing Young's analysis in particular but also going against the tide in arguing that China is a relatively well-integrated nation-state and is becoming more so over 
time. He makes the point that regional integration cannot be separated from an understanding of enterprise reform, privatisation and marketisation, noting, for example, that organisational changes at the enterprise level-such as conversions of state firms to joint stock companies-are making it more costly for local governments to intervene in market operations. While challenging the views of most other authors, Naughton agrees that further efforts to integrate the domestic market are called for, and he sees China's challenge as consisting of two types of integration.

The first consists of building adequate infrastructure to permit adequate transport of bulky, energy-intensive commodities and fuels at reasonable cost. The second consists of creating a unified competitive marketplace in which enterprises can exploit productivity differentials and comparative advantage so that the economy as a whole can reap gains from trade. Progress has been made in these areas, but much more needs to be done (Naughton 2003:205).

There have inevitably been comparisons drawn between China's-or, more aptly, coastal China's-exceptional integration into the global economy and the perceived lack of progress internally. About the same time as the first World Bank study, Ash and Kueh (1993) noted that increasing integration of southern China (Guangdong and Fujian) with Hong Kong and Taiwan contrasted withand could indeed have contributed to-poor internal integration in the sense that backward and forward linkages between the south and the rest of China remained weak. Poncet (2003) uses data on provincial trade flows to compare the magnitude and evolution of Chinese provinces' engagement in domestic and international trade, and confirms Ash and Kueh's findings on a bigger scale one decade later. She shows that China's increasing openness in international markets has gone hand in hand with internal fragmentation between 1987 and 1997, and concludes that while reforms obviously succeeded in promoting the former, they have failed to reduce impediments to the latter.

$\mathrm{Fu}(2004)$ argues that the emphasis on foreign direct investment (FDI) driven labour-intensive processing industries in the rapidly developing southeastern coastal provinces has attracted relatively mobile and efficient resources from the inland regions, but it has generated only limited linkages and weak spillovers in return-thereby describing a situation in which polarisation effects are dominating trickle down. Yao and Zhang (2001) confirm this, and attribute the divergence in regional incomes to the slow process of spillovers from the coastal region inwards. Hu and Jefferson (2002), drawing on evidence from China's electronic and textile industries, take this point a step further in establishing that FDI enhances the productivity of the recipient firm, but it depresses that of non-FDI firms, whether located nearby or not. While their findings suggest that 
non-FDI firms will eventually catch up in terms of productivity in the longer term, the short-term implications are that trickle down is limited even within coastal cities where FDI is concentrated, let alone across to other areas. In sum, there seems to be ample evidence that the better-developed coastal region is becoming better integrated with the rest of the world than it is with the rest of China.

That is not to say that transmissions of inter-regional growth are completely absent within China. Ying (2000) uses provincial output data and finds the strongest significant influence being exerted by Guangdong, which has significant GDP growth correlations with four of its five contiguous provinces, although, notably, two of those correlations are negative, not positive. Brun et al. (2002) and Zhang and Felmingham (2002) find evidence of spillovers from the coastal region to the central region and, in the latter, to the western region as well. Groenewold et al. (2006) use annual GDP data for three regions (coastal, central and western) and find strong spillovers from the coast to the other regions and from the central to the western region, but none from the western region to anywhere else. Groenewold et al. (forthcoming) extend the analysis to six regions and conclude that the three core regions forming China's industrial heartland—-the southeast, the Changjiang River region and the Yellow River region-are relatively well interconnected. Even across these regions, however, they find that the spillover effects are neither pervasive nor strong, while effects are even weaker or entirely absent elsewhere. ${ }^{4}$ Thus, while there is some evidence that some growth is being transmitted from the betterdeveloped regions to the rest of the country, none of the results are indicative of a highly integrated national economy in which the regions depend increasingly on each other for their prosperity rather than on themselves alone.

\section{China's inter-regional growth spillovers}

As the preceding section demonstrates, a wide range of approaches has been used for assessing the strength of regional integration in China and researchers are far from agreed on the extent of integration implied by their results. Despite this diversity, one common theme appears to be that the regions making up China's industrial core are becoming more integrated with each other (and with the rest of the world) than they are with the rest of the country. This section provides the results of a spillover analysis to directly address the interregional transmission of growth among China's regions. The limited extent of transmissions - as one of the key components of the integration issue-lends further support to this developing consensus.

The model used to generate the estimates of inter-regional spillovers is a VAR model estimated using data for six Chinese regions, given as follows: 
southeast, SE (Guangdong [including Hainan], Fujian and Guangxi); Changjiang River, CR (Shanghai and Jiangsu, Zhejiang, Hubei, Hunan, Jiangxi and Anhui); Yellow River, YR (Inner Mongolia, Henan, Shanxi, Beijing, Tianjin, Shandong and Hebei); northeast, NE (Heilongjiang, Jilin and Liaoning); southwest, SW (Yunnan, Guizhou, Sichuan and Chongqing); and northwest, NW (Xinjiang, Gansu, Qinghai, Ningxia and Shaanxi). ${ }^{5} \mathrm{~A}$ map of the regions is provided in Figure 10.1.

The results are based on the estimated VAR model in Groenewold et al. 2006. As argued there, the VAR model is well suited to our application: it does not require a prior theoretical specification (an advantage when there are so many competing theories) and it is parsimonious in its data requirements (a decided advantage when working with Chinese data). The absence of a theoretical framework does, however, have a cost in terms of interpretation, which is necessarily more speculative than it would be had we estimated a more complex structural model.

\section{Figure 10.1 The six regions of mainland China}

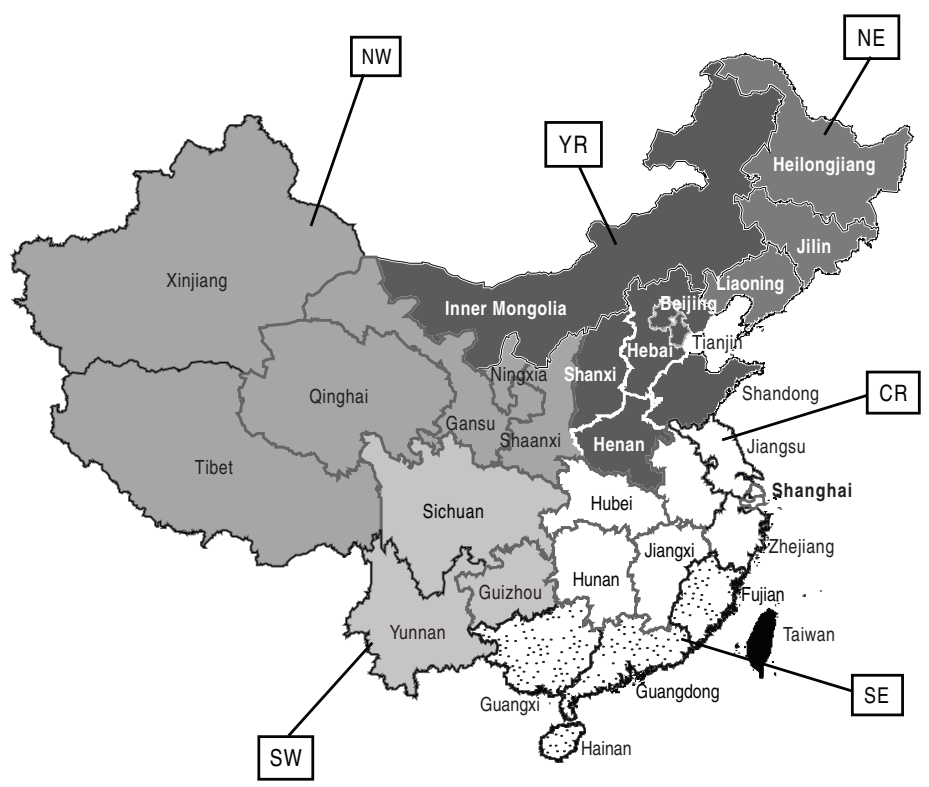


The VAR model consists of a set of dynamic equations of the form

$$
Y_{i t}=\beta_{i 0}+\beta_{i 1} Y_{1 t-1}+\beta_{i 2} Y_{2 t-1}+\ldots+\beta_{i n} Y_{n t-1}+\varepsilon_{i t}, \quad i=1,2, . ., n
$$

where the $\beta$ s are constants to be estimated, $Y_{i t}$ is log output for region $i$ in period $t$ and $\varepsilon_{i t}$ is the error term for the ith region. More lags of each $Y$ can be added to the right-hand side without affecting the argument that follows.

The model parameters can be estimated from time-series data for regional outputs. The estimated model is then used to analyse spillovers by shocking one of the error terms (say, $\varepsilon_{j}$ ) for one period and following through the effects on all regional outputs in the current and subsequent periods. The effects of a shock in period $t$ to $\varepsilon_{j}$ on regional outputs from time $t$ to some future time ( $t+15$ in our analysis) are captured by impulse response functions (IRFs). There will be $n^{2}$ IRFs associated with the model, one for each $Y_{i}$ and $\varepsilon_{j}$ combination; the value of the $i j$ th IRF for period $\tau$ is the effect of a shock to $\varepsilon_{j}$ on $Y_{i}$, $\tau$ periods after the shock occurred. We use the IRFs as measures of spillovers from the shocked region to the other regions.

There is one complication in what follows. The above explanation assumes that it is reasonable to shock one $\varepsilon_{j}$ independently of the others. In practice, however, the error terms can be correlated with each other and this correlation needs to be taken into account in the simulation exercise. The most common way to do this is to transform the error terms to make them independent, using a Choleski procedure and then to shock the transformed errors. ${ }^{6}$ Unfortunately, the resulting IRFs are not independent of the order in which the variables are entered into the model - an order that could be arbitrary to some extent. This dependence on order is particularly pronounced when the residuals derived from the estimation of (1) are strongly correlated with each other. This is the case in our application to regional spillovers in China.

There are various ways of addressing this ordering problem. One-not uncommon in the application of VARs-is to ignore it and assume that the errors are independent or, at least, that it makes sense to shock them independently. Another is to argue that a particular ordering is more appropriate than others. A further alternative, which we follow, is to conjecture about the source of the residual correlation and base the resolution on this conjecture. We argue that the strong residual correlation is due to an important common component to regional shocks, which is caused by national shocks that have an impact on all regions. If this is the case, we ought to be able to resolve the ordering problem by accounting for the common national shock. At least two methods can achieve this: 1) purge the regional output series of the common national component 
by a preliminary regression of each regional output on national output, and 2) include the national output variable in the VAR together with the regional outputs and order national output first. The second method works because IRFs based on the Choleski decomposition assign any common component of the shocks to the first variable, so if the correlation is due to a national shock and the first variable is national output, the procedure based on the Choleski decomposition will correctly assign the common component to national output. In this application, we use the second method. It turns out that the resulting IRFs are not sensitive to ordering as long as national output is ordered first, lending some support to our conjecture that national shocks are the source of the common correlations.

The data we use are based on provincial real GDP for the period 1953-2003. The sources of the data are twofold: the early data come from Wu (2004), who obtained the 1953-95 series from The Gross Domestic Product of China, 1952-95 (National Bureau of Statistics 1997). Data for 1996-2003 come from the Statistical Yearbook of China (National Bureau of Statistics various years).

The data are in log form and all series are tested for stationarity before specifying the model. The (log) regional outputs (and national output) are all stationary about trend as long as a break in trend at 1978 and level breaks at 1966 and 1978 are allowed for. We therefore specify the model in log levels with these breaks. Two lags are sufficient to remove autocorrelation from the residuals.

We estimate the model using data for the entire 1953-2003 period, despite the dramatic changes in economic organisation and structure during this period, which will almost certainly have affected the nature of spillovers. In particular, the opening up of the economy since 1978 after a long period of central planning and a policy of regional self-sufficiency led to a strong presumption of structural change in our model. We would have liked to estimate the model separately over the pre and post-1978 periods - to improve parameter stability and to test hypotheses about the nature of changes in spillovers during our sample. Limited experimentation with sub-period estimates made it clear, however, that there were not enough data points in the two sub-periods to adequately estimate the model and we had to base our results on the model estimated over the entire 1953-2003 period (but allowing for trend and intercept breaks at 1978).

The VAR results show a high explanatory power for all the equations-not surprisingly given that they are specified in log levels and all include a trend as well as break variables. The national output variable (NAT) is significant in all equations at one lag (at least) with the exception of the southwest region, where it is only marginally significant, suggesting that this region could be related only weakly to the national economy. 
The estimated VARs can be used to generate 49 IRFs associated with this seven-equation model (six regions plus the national equation) and we use the 36 IRFs associated with the regional output equations to assess regional spillovers. Space constraints make it impossible to report them all and we report one set (for a shock to SE region output) and summarise the implications of the remainder in Table 10.1. The IRFs that capture the effects of a unit shock to SE output on each of the regions are pictured in Figures 10.2 and 10.3. ${ }^{7} \mathrm{We}$ compute the IRFs and the cumulative IRFs, the latter being the accumulation over time of the IRFs.

Figures 10.2 and 10.3 show that in the short term the strongest effect of a shock to SE is on SE itself. Over time, there is also a substantial effect on CR and YR and these effects overshadow that on SE itself after seven or eight years. There are effectively no spillovers to NE and SW, and the overall effects on NW are negative.

The model is specified in terms of logs so that the values of the IRFs have the dimension of elasticities of output in one region with respect to a shock

Table 10.1 Summary of spillover effects

\begin{tabular}{lcrrrrr}
\hline & \multicolumn{7}{c}{ Shock to } \\
Effect on & SE (8) & CR (9) & YR (13) & NE (10) & SW (12) & NW (7) \\
SE: SR & 0.7546 & 0.0716 & 0.0733 & 0.0858 & 0.0825 & 0.0801 \\
$\quad$ Max & 1.2634 & -0.2056 & -0.5986 & -0.1009 & -0.5868 & -0.3982 \\
CR: SR & 0.2834 & 0.6163 & 0.2520 & 0.2948 & 0.2836 & 0.2752 \\
$\quad$ Max & 5.0284 & 0.0261 & 0.5655 & 0.5541 & -0.8673 & 0.0852 \\
YR: SR & 0.2198 & 0.3298 & 0.5359 & 0.3624 & 0.3486 & 0.3383 \\
$\quad$ Max & 2.9103 & -0.1907 & 0.5365 & 0.3330 & -0.0836 & 0.4044 \\
NE: SR & 0.1788 & 0.3107 & 0.3411 & 0.5287 & 0.2564 & 0.2488 \\
Max & 0.4696 & -0.1057 & 0.3253 & 0.2673 & 0.7172 & -0.1115 \\
SW: SR & 0.1016 & 0.0135 & 0.0517 & -0.0526 & 0.5436 & 0.0758 \\
$\quad$ Max & 0.1071 & 0.0113 & 0.0004 & -0.1385 & 0.569 & 0.4946 \\
NW: SR & 0.0549 & 0.0559 & 0.0705 & 0.0887 & 0.1337 & 0.3062 \\
$\quad$ Max & -0.3357 & -0.0282 & -0.1013 & -0.0864 & 0.2288 & 0.2157 \\
Mean GDP & 93 & 252 & 210 & 97 & 54 & 42 \\
& & & & & & \\
\hline
\end{tabular}

Note: Numbers measure the effect on the row region of a one-unit shock to the output of the column region. The numbers in the 'SR' rows represent short-term (first-period) effects and the numbers in the 'Max' rows measure the effect when the cumulative effect is at its maximum. The numbers in parentheses in the column headings are the number of years after the shock when the maximum occurs. The mean GDP figures in the last row are in terms of billions of yuan in 1953 prices.

Source: Authors' calculations. 


\section{Figure 10.2 IRFs for a shock to SE}

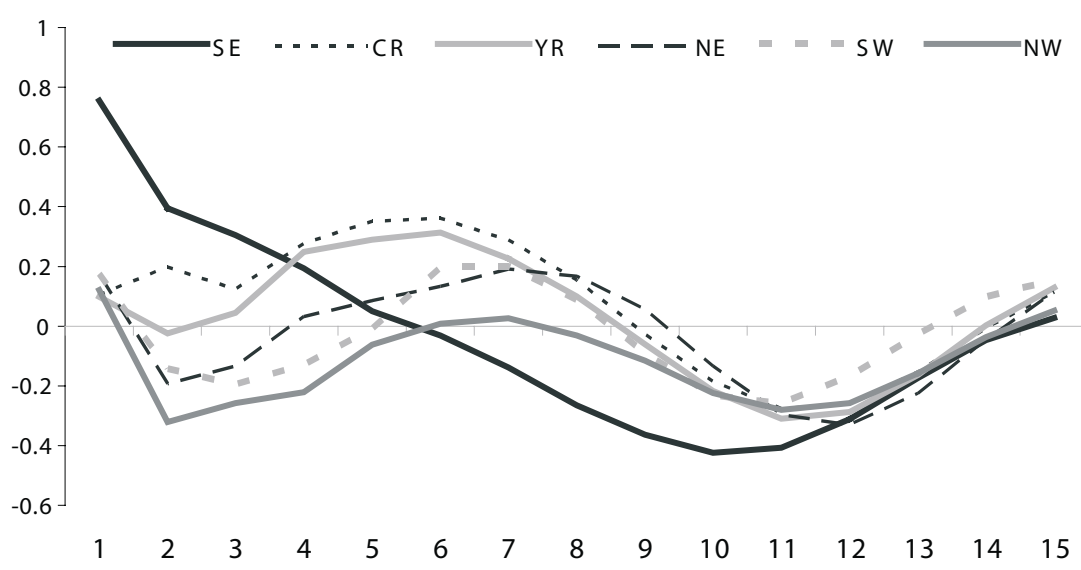

Source: Authors' calculations.

Figure 10.3 Cumulative IRFs for a shock to SE

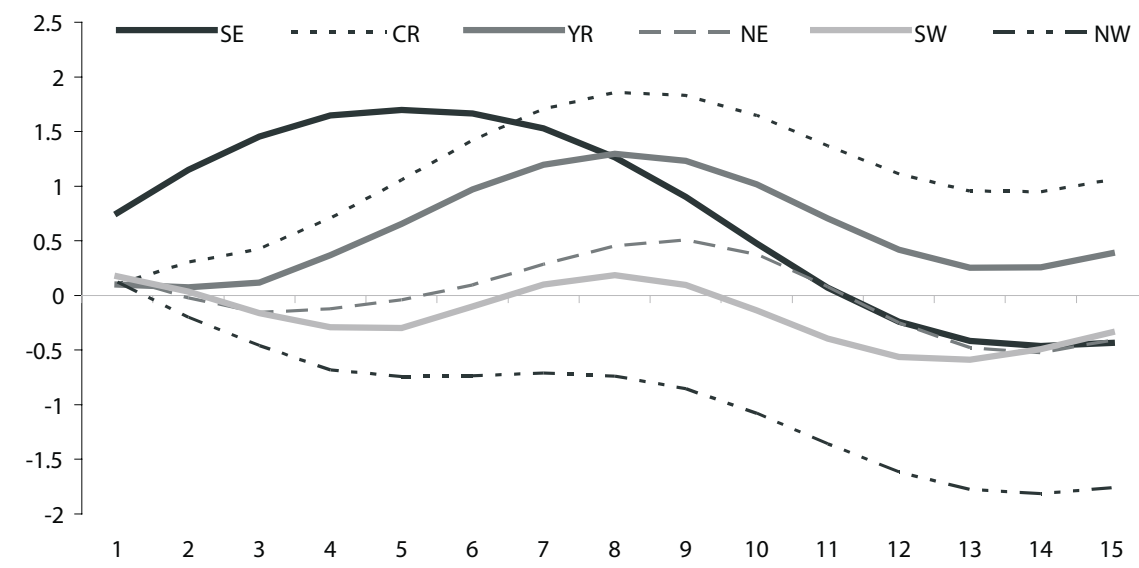

Source: Authors' calculations. 
to output in another region. Since the regions are of very different sizes, the elasticities are difficult to compare across regions, so we convert them to levels at the sample means and report summary measures in Table 10.1. The table gives results for the impact (that is, within-the-year) effect and the cumulative effect at its maximum. The date of the maximum cumulative effect for the shock to SE output pictured in Figure 10.3 was chosen to be eight years. Table 10.1 shows, for example, that the effect of a one-yuan shock to SE output was to increase CR output by 0.2834 yuan in the year of the shock and by a cumulative amount of 5.0284 yuan at its maximum effect after nine years. The first column of figures therefore summarises all the cumulative IRFs in Figure 10.3.

The effects of a shock to the $\mathrm{SE}$ region seem plausible. The strongest positive spillovers by far are on the $\mathrm{CR}$ and $\mathrm{YR}$ regions, which is not surprising given the contiguity of the SE and CR regions and also the dominance of these three regions in China's industrial output (producing, for example, close to 80 per cent of all manufacturing output in the early 1990s). It is prima facie surprising that there seems little evidence of a spillover to the other adjoining region, SW-although the lack of a connection here could simply reflect the quite different structure of the two regions as well as the lack of backward linkages from the SE to the SW region. It shows that contiguity does not guarantee spillovers. The lack of effect on the NE region could be explained by the large distance between the regions and the fact that the NE region has a relatively obsolete industrial structure and few resources. An overall negative spillover might normally be explained as evidence that a boost to one region attracts resources that would otherwise have gone to the other region and therefore shows a decline in the output of the second region. In the case of the relationship between the SE and NW regions, it could reflect the reallocation of public investment resources away from the coastal regions to the inland regions and vice versa at times during the sample period.

The second column of Table 10.1 summarises the effects of a shock to the Changjiang River region and shows that the initial effects are dominated by those on the $\mathrm{CR}$ region itself, although there are also marked effects on the YR and NE regions. Over time, all spillovers are relatively small, with negative effects on the SE, YR and NE regions. Thus, it appears that, in the short term, the NE region is related more closely to the $\mathrm{CR}$ region than to the SE region, which is not unexpected. The subsequent effects, however, show that shocks to the $\mathrm{CR}$ region have at best short-term positive spillovers, particularly on the $\mathrm{NE}$ and $\mathrm{YR}$ regions.

A shock to the Yellow River region shows that the initial effects are dominated by those on the region itself, although there are also substantial short-term 
effects on the CR and NE regions. It is interesting that the spillover to NE is larger than spillovers to NE from CR and SE, which suggests that geographic proximity matters in this case. This is borne out by the negligible spillovers to the SE, SW and NW regions. In the longer term, the spillovers are very modest: the largest are to YR itself and to $\mathrm{CR}$, but these are small compared with the long-term effects of spillovers from SE. The combination of positive growth spillovers from SE to YR and CR, combined with limited spillovers in the opposite direction, suggests that upstream industries in the latter two regions could benefit from growth of downstream industries in the former, while the reverse does not seem to be true.

The IRFs showing the effects of a shock to the NE region show that the short-term effect of a shock to this region is dominated by the effect on the region itself, although there are small spillovers to the $C R$ and $Y R$ regions. There are no short-term spillovers to the SE, SW and NW regions. In the longer term, the results of a NE shock are small, the largest being on CR, while spillovers to the SE, SW and NW regions are negative (but small absolutely). Thus, we can conclude that the linkages from the NE region to the rest of the country are weak in the short and the long term, which suggests that it is relatively isolated economically from the rest of the country-perhaps handicapped by its increasingly outmoded industrial base, as recognised by the recent policy to 'revitalise the northeast' (Geng and Weiss 2005).

A shock to the southwest region has small positive short-term spillovers to all other regions except the SE region, suggesting again that contiguity is not sufficient for strong linkages. Over time, many of these are reversed so that the cumulative effects are negative, although there is a substantial continuing effect on NE and a smaller one on NW. The latter can be explained by its close proximity but this cannot explain the effect on the NE region, which is at the opposite corner of the country.

Finally, the initial effects of a shock to the NW region are similar to those for the SW region except that now there is effectively no spillover to the SW region, whereas there was from SW to NW. Over time, the largest spillover is to SW (despite the absence of a short-term effect between these regions), and there is also a modest effect on YR. Long-term spillovers to other regions are negligible or negative. This supports the notion that the northwest's dominance in coal, natural gas and oil production has resulted in an energy-industry enclave, which offers little in terms of transmitting growth towards the rest of the country.

To sum up the implication of the IRFs, overall spillovers are relatively weak. Not unexpectedly in light of earlier literature, the SE region has the largest sustained spillovers but these are limited to the $C R$ and $Y R$ regions. The $C R$ and 
YR regions have modest spillover effects and these are limited to the $C R, Y R$ and NE regions, with (surprisingly) little effect on SE. The NW and SW regions have weak linkages - they are little affected by shocks to other regions and, in turn, have little effect on the rest of the country. Thus, these core industrial regions of China (SE, CR and YR) appear to be relatively well integrated (although this is uni-directional in SE's case), the western regions are connected only loosely and the NE receives small spillovers from most other regions but has positive effects only on the core $C R$ and $Y R$ regions.

\section{Conclusions}

Regional integration has been a major policy challenge throughout China's history, and remains so today. Broadly defined as the increasing interdependence of regions as reflected in the flow of goods, services and/or factors of production, integration, so we have seen, can be promoted from 'below', by the removal of impediments to trade and factor mobility, and from 'above', by the active promotion of economic cooperation through appropriate policies or institutions. The transition away from the former system of command planning -in which planning was deliberately compartmentalised along provincial lines and in which the policy of self-sufficiency encouraged provincial independence-should in itself have spurred improvements in inter-provincial relations, with integration following as a natural consequence of development in an increasingly market-based economy. Yet the bulk of the evidence suggests that China's regions do not appear to be as highly integrated as they should be. Given the wide range of definitions and methodologies available for assessing the extent and dynamic pattern of integration, it is unlikely that any one piece of research will provide a definitive assessment of China's integration issue. Instead, this chapter has contributed a small piece to what is quite clearly a large and complex puzzle.

Our own empirical results contribute to a developing consensus indicating that integration among China's industrial core regions has proceeded further than their integration with the rest of the country. In particular, the positive transmission of growth from the southeast towards the Yellow River and Changjiang River regions implies that when the first region performs well, the last two regions benefit, while the rest of the country receives little impetus to their own regional rates of growth. With these three regions containing the country's eight richest provinces and only two of the country's eight poorest, a major cause of concern is that China is becoming polarised into a set of relatively well-integrated and developed regions and a set of isolated and underdeveloped outsiders-hardly an optimal scenario for national unity, economic and social 
stability and, perhaps most crucially, preserving political power. Furthermore, the one-way street of spillovers from the southeast region to the Yellow River and Changjiang River regions, but not in return, suggests that China is heavily reliant on the former region - and on Guangdong in particular-for sustaining its rapid rate of GDP growth. Although this 'engine of growth' has served China well to date, a slow-down in the southeast region will impact negatively on the main industrial centres, while receiving little offset in terms of positive growth spillovers from elsewhere in the country. A key challenge for the government, then, is to improve the positive transmissions of growth among China's regions.

One of the major limitations of the VAR model is that it says nothing about the channels by which spillovers are transmitted, so we can only conjecture as to why certain regions appear to be more integrated than others. Still, it provides a useful take-off point for further investigation of this issue. Why, for example, are the benefits of growth in the southeast region failing to reach the contiguous southwest, and what could be done to improve this situation? How important are transport linkages between these regions, and what about the attitudes of local governments towards promoting inter-regional trade? Are the southeast, Yellow River and Changjiang River regions more highly integrated because of common industrial structures or because of complementary industrial structures (that is, underpinned by intra-industry or inter-industry trade, respectively)? Are the northeast and northwest isolated because of failures to promote integration from above or below? Answers to these questions-and many more-will help to identify the appropriate role of the central and local governments in improving integration in the future.

One thing, however, is clear: a comprehensive approach towards domestic market integration is essential, since partial reforms run the risk that the costs of integration will outweigh the benefits. For example, the government needs to ensure not only that impediments to inter-regional trade are minimal, but that less-developed regions have the capacity to benefit from technological transfers embodied in that trade. Perfectly mobile labour in the absence of fully developed capital markets could result in excessive migration out of less-developed areas (with the consequent brain drain there and rising congestion pressures in industrial centres), without investments flowing in or innovations trickling down. If the recent findings of the World Bank (2005) are accurate, much remains to be done to reduce the misallocations of capital across regions and to prevent further fragmentation of regional capital markets, thereby enabling investment funds to be channelled to those regions most in need. Nationally uniform regulations and institutions designed to minimise inter-regional barriers to trade and transaction costs also have an important role to play. 
A further limitation in the application of the VAR model to China is that data constraints make it necessary to use the entire period from 1953 to 2003, while ideally the command and reform periods would have been analysed separately. The analysis is undeniably a little clouded by the fact that integration was deliberately discouraged in the command era, and also by the fact that during this time the transmission of growth from one region to another presumably had more to do with central government decisions than with the market-based transmissions of growth described above. To the extent that integration has improved over time, our results will understate the strength of inter-regional linkages today. However understated they might be, they do not indicate the need for an alarmist view of potential internal disintegration within China, but rather that more research remains to be done.

\section{Notes}

1 Winters 2004 reviews the mechanisms by which trade could impact on growth.

2 Dowrick and Golley (2004) provide empirical evidence that, since the 1980s, the benefits of trade have accrued mainly to richer countries, with little benefit for less-developed ones.

3 This section draws on Golley (2007).

4 This finding confirms state media reports that 'administrative disintegration' has resulted in redundant industrial construction within the Yangtze (Changjiang) River Delta, with 11 of the 15 major cities concentrating on spare auto parts manufacturing, and 12 on telecommunications. Meanwhile, vicious competition is hurting the overall prosperity of the region. Calls are being made to improve financial cooperation and to standardise qualifications, taxes and regulations within the area. Similarly, the Pearl River Delta's market accession restrictions_-'the area's most pressing problem'-need to be eliminated (Beijing Review 2003:35).

5 For greater detail on the reasons for the definition of the regions and a general description of their characteristics, see Groenewold et al. (forthcoming).

6 For a recent textbook treatment of this procedure, see Enders (2004:Chapter 5).

7 While it is common to compute IRFs based on one-standard-deviation shocks, we use unit shocks. This allows for easier comparison of results across regions and implies that the IRFs have the dimension of elasticities. For each simulation, we shock the region in question as well as national output in order to incorporate the constraint that, in terms of levels, the regional outputs add to national output so that it is not possible to shock one region's output-holding all other regional outputs constant-without allowing for the consequent contemporaneous effect on national output. In log terms, we shock the national log output by the same as the shock to regional output multiplied by its share in national output. The order of the variables/regions underlying these IRFs is NAT, SE, CR, YR, NE, SW and NW. Experimentation with alternative ordering of the regional outputs shows that our overall conclusions are not affected. 


\section{References}

Abramovitz, M., 1986. 'Catching up, forging ahead, and falling behind', Journal of Economic History, 46:385-406.

Ash, R. and Kueh, Y.Y., 1993. 'Economic integration within Greater China: trade and investment flows between China, Hong Kong and Taiwan', China Quarterly, 136:711-45.

Bai, C.-E., Du, Y., Tao, Z. and Tong, S.Y., 2004. 'Local protectionism and regional specialization: evidence from China's industries', Journal of International Economics, 63:397-417.

Beijing Review, 2003. 'Tale of two deltas', Beijing Review, 31 July:34-5.

Boyreau-Debray, G. and Wei, S.-J., 2004. Can China grow faster? A diagnosis of the function of its domestic capital market, IMF Policy Discussion Papers 04/76, International Monetary Fund, Washington, DC.

Brun, J.F, Combes, J.L. and Renard, M.F., 2002. 'Are there spillover effects between coastal and non-coastal regions in China?', China Economic Review, 109:1-9.

Donnithorne, A., 1967. China's Economic System, George Allen and Unwin, London.

__, 1972. 'China's cellular economy: some economic trends since the Cultural Revolution', China Quarterly, 52:605-91.

Dowrick, S. and Golley, J., 2004. 'Trade openness and growth', Oxford Review of Economic Policy, 20(1):38-56.

Enders, W., 2004. Applied Econometric Time Series, Second edition, Wiley, Hoboken, NJ.

Fan, C.S. and Wei, X., 2003. 'The law of one price: evidence from the transitional economy of China.' Available from www.hiebs.hku.hk/events_updates/pdf/ weixiangdong.pdf

$\mathrm{Fu}, \mathrm{X} ., 2004$. 'Limited linkages from growth engines and regional disparities in China', Journal of Comparative Economics, 32:148-64.

Geng, X. and Weiss, J., 2005. Development in North East People's Republic of China: an analysis of enterprise performance, 1995-2002, Asian Development Bank Institute Discussion Paper, No. 34, Asian Development Bank, Manila.

Golley, J., 2007. The Dynamics of Chinese Regional Development: market nature, state nurture, Edward Elgar, Cheltenham.

Groenewold, N., Lee, G. and Chen, A., 2006. Inter-regional output spillovers in China: disentangling national from regional shocks, Economics Discussion Paper 06-25, University of Western Australia, Perth. 
_- (forthcoming). 'Inter-regional spillovers in China: the importance of common shocks and the definition of the regions', China Economic Review.

Hirschman, A., 1958. The Strategy of Economic Development, Yale University Press, New Haven, Conn.

Howitt, P., 2000. 'Endogenous growth and cross-country income differences', American Economic Review, 90(4):111-30.

$\mathrm{Hu}, \mathrm{A}$. and Jefferson, G., 2002. 'FDI impact and spillover: evidence from China's electronic and textile industries', World Economy, 38(4):1,063-76.

Lucas, R.E., 1988. 'On the mechanics of economic development', Journal of Monetary Economics, 22(1):3-42.

Lyons, T., 1987. Economic Integration and Planning in Maoist China, Columbia University Press, New York.

Marshall, A., 1920. Principles of Economics, Macmillan Press, London.

Naughton, B., 2003. 'How much can regional integration do to unify China's markets?', in N. Hope, D.T. Yang and M.Y. Li (eds), How Far Across the River? Chinese Policy Reform at the Millennium, Stanford University Press, California:204-32.

National Bureau of Statistics, various years. Statistical Yearbook of China, China China Statistical Press, Beijing.

——, 1997. The Gross Domestic Product of China, 1952-95, Dongbei University of Finance and Economics Press, Dongbei.

-_, 2006. China Statistical Abstract 2006, China Statistical Press, Beijing.

Parsley, D.C. and Wei, S.J., 1996. 'Convergence to the law of one price without trade barriers or currency fluctuations', Quarterly Journal of Economics, 111(4):1,211-36.

Poncet, S., 2003. 'Measuring Chinese domestic and international integration', China Economic Review, 14:1-21.

_- 2005. 'A fragmented China: measure and determinants of Chinese domestic market disintegration', Review of International Economics, 13(3):409-30.

Romer, P.M., 1990. 'Endogenous technological change', Journal of Political Economy, 98(5):S71-102.

Tan, K. and Zhang, X., 2005. Incremental reform and distortions in the product and factor market in China, Paper prepared for the Stanford Center for International Development annual conference, China's Policy Reforms: progress and challenges, 29 September-1 October, Stanford University.

Tang, K.K., 1998. 'Economic integration of the Chinese provinces: a business cycle approach', Journal of Economic Integration, 13:549-70.

Tinbergen, J., 1965. International Economic Integration, Elsevier Publishing Company, Amsterdam. 
Winters, L.A., 2004. 'Trade liberalisation and economic performance: an overview', Economic Journal, 114(493):F4-21.

World Bank, 1994. China: internal market development and regulation, World Bank Report, No. 12291-CHA, Washington, DC.

- - 2005. China: integration of national product and factor markets: economic benefits and policy recommendations, Report, No. 31973-CHA, 13 June, Washington, DC.

Wu, Y., 2004. China's Economic Growth: a miracle with Chinese characteristics, Routledge Curzon, London.

Xu, X., 2002. 'Have the Chinese provinces become integrated under reform?', China Economic Review, 13:116-33.

$\mathrm{Xu}, \mathrm{X}$. and Voon, J.P., 2003. 'Regional integration in China: a statistical model', Economics Letters, 79:35-42.

Yao, S. and Zhang, Z., 2001. 'On regional inequality and diverging clubs: a case study of contemporary China', Journal of Comparative Economics, 29:466-84.

Ying, L.G., 2000. 'Measuring spill-over effects: some Chinese evidence', Papers in Regional Science, 79:75-89.

Young, A., 2000. 'The razor's edge: distortions and incremental reform in the People's Republic of China', Quarterly Journal of Economics, 15(4):1,091135.

Zhang, Q. and Felmingham, B., 2002. 'The role of FDI, exports and spillover effects in the regional development of China', Journal of Development Studies, 38:157-78. 